\title{
ACCIÓN COLECTIVA Y ACCIÓN INDIVIDUAL \\ PARA LA DEFENSA DE LOS DERECHOS \\ DE LOS CONSUMIDORES
}

\section{Class action and individual action for the protection of consumers rights}

\author{
FAUSTINO CORDÓN MORENO \\ Universidad de Navarra \\ fcordon@unav.es
}

Cómo citar/Citation

Cordón Moreno, F. (2017).

Acción colectiva y acción individual para la defensa

de los derechos de los consumidores.

Derecho Privado y Constitución, 31, 217-242.

doi: https://doi.org/10.18042/cepc/dpc.31.05

(Recepción: 24/07/2017. Aceptaciòn tras revisión: 16/10/2017. Publicación: 27/11/2017)

Resumen

En el trabajo se analiza críticamente la jurisprudencia del Tribunal Constitucional y del Tribunal Supremo que, aceptando la doctrina establecida por el Tribunal de Justicia de la Unión Europea, sanciona la independencia, con algunos matices, de la acción colectiva y la acción individual para la tutela de los derechos de los consumidores.

\section{Palabras clave}

Tutela de los consumidores; acción colectiva; acción individual; litispendencia; cosa juzgada; prejudicialidad. 


\section{Abstract}

This work aims at critically analyzing the jurisprudence of both the Constitutional Court and the Supreme Court of Spain that, following the doctrine of the Court of Justice of the European Union, sanctions the independence of the collective action and the individual action brought in the defense of consumers rights.

\section{Keywords}

Consumer protection; collective action; individual action; litispendence; res judicata; prejudmental issue. 


\section{SUMARIO}

I. INTRODUCCIÓN. II. LAS POSTURAS EXISTENTES EN LA JURISPRUDENCIA. III. LA STJUE DE 14 DE ABRIL DE 2016. IV. LA STC 148/2016, DE 19 DE SEPTIEMBRE. V. LA RECEPCIÓN DE LA DOCTRINA POR EL TRIBUNAL SUPREMO. VI. PRECISIONES A LA DOCTRINA PRECEDENTE: LA EFICACIA SECUNDUM EVENTUM LITIS DE LA SENTENCIA DICTADA EN EL PROCESO EN QUE SE EJERCITA LA ACCIÓN COLECTIVA. LA STS 367/2017, DE 8 DE JUNIO. VII. CONCLUSIONES CRÍTICAS. BIBLIOGRAFÍA.

\section{INTRODUCCIÓN}

Abordo en este trabajo uno de los problemas procesales más complejos que plantea la tutela de los derechos de los consumidores: a saber, la relación entre un proceso en que se ejercita la acción para la tutela de los derechos e intereses colectivos o difusos de los consumidores (arts. 11.2 y 3 de la Ley de Enjuiciamiento Civil [LEC]) y los procesos iniciados con posterioridad por consumidores particulares para la tutela de su derecho estrictamente individual al amparo de la legitimación que les reconoce el art. 11.1 LEC. Se plantea si existe entre ambos procesos - colectivo e individual — una relación de prejudicialidad o acaso de litispendencia como una anticipación de la eventual eficacia de la cosa juzgada en el segundo de ellos de la sentencia firme dictada en el primero.

El problema que planteo se encuentra latente en la LEC, cuyo art. 11 reconoce la legitimación para la defensa de los intereses tanto individuales como colectivos y difusos, sin supeditar la primera (legitimación individual) a la segunda ${ }^{1}$; $y$ adquirió relevancia práctica con el proceso iniciado en 2010 por

1 En el citado art. 11 LEC se observa una contraposición entre la legitimación para demandar en juicio en defensa de los intereses colectivos y en defensa de los intereses difusos de los consumidores y usuarios, radicando la diferencia entre uno y otro tipo no tanto en la naturaleza de los intereses en cuestión como en el grado de determinación o determinabilidad de los consumidores y usuarios interesados. Pues bien, a la vista de dicho precepto, se puede afirmar — en lo que ahora interesa considerar- que las asociaciones tienen reconocida legitimación no solo para el ejercicio de acciones de cesación (de una conducta contraria a la ley y perjudicial para los consumidores) y/o 
la Asociación de Usuarios de Banca, Caja y Seguros (ADICAE), en el Juzgado de lo Mercantil núm. 11 de Madrid, contra más de un centenar de entidades que aplicaron la cláusula suelo en sus contratos de préstamo hipotecario, ejercitando, acumuladas, las acciones de nulidad y de cesación de la cláusula suelo y la acción de condena de las entidades financieras demandadas a abonar a los consumidores perjudicados las cantidades pagadas en exceso (la diferencia existente entre el tipo de interés pactado y el satisfecho en aplicación de la cláusula suelo).

La pendencia de este proceso fue invocada por las entidades financieras demandadas que alegaron la excepción de litispendencia (art. 421 LEC) o la de prejudicialidad civil, al amparo del art. $43 \mathrm{LEC}$, en los procesos posteriores iniciados por consumidores particulares para la defensa de su derecho o interés exclusivamente individual. Sin embargo, antes de analizar las diferentes respuestas que encontró el planteamiento de esta excepción, parece conveniente precisar, siquiera sea brevemente, los conceptos que se manejan, en especial, los de prejudicialidad y litispendencia.

$\mathrm{Al}$ respecto, recuerda la Sentencia del Tribunal Supremo (STS) de 18 de junio de 2007 (RJ 2007/3526)² que la Sala de lo Civil del TS ha dicho:

[...] con reiteración que la litispendencia es una figura procesal cuya interpretación teleológica coincide plenamente con la de la cosa juzgada, que sirve de anticipo de aquella, y que, con carácter preventivo o cautelar, busca evitar posibles sentencias contradictorias. Por esta razón, con carácter general, al igual que para apreciar aquella, también se exige para estimar la excepción dilatoria de litispendencia que concurra una triple identidad: objetiva, subjetiva y causal, entre el pleito o pleitos precedentes y aquel en que se haga valer la excepción [...]

Ciertamente, hasta tiempos recientes, la jurisprudencia ha extendido la eficacia de la excepción de litispendencia «también a los casos en que, faltando esa triple identidad, lo discutido en un pleito pendiente pueda llegar a interferir o prejuzgar el resultado de otro posterior, con riesgo de fallos contradictorios en asuntos interdependientes». Pero lo ha hecho bajo la vigencia de la LEC de 1881, por la falta de previsión de un cauce propio para los casos de prejudicia-

que no se reitere en el futuro o de nulidad (de una cláusula contractual lesiva), sino también para ejercitar acciones reparadoras (con el fin de obtener el resarcimiento de los perjudicados u otros fines que afectan directamente al derecho subjetivo de los mismos). Y ello con independencia de que los consumidores eventualmente beneficiados estén determinados (o sean determinables) o no. Más adelante, me refiero a ambos tipos de legitimación cuando se ejercitan acciones reparadoras o indemnizatorias.

2 Véase, también, la STS 882/2008, de 26 de septiembre de 2008 (RJ 2009/133). 
lidad (civil) y con el fin de conjurar el riesgo de resoluciones contradictorias; porque esta jurisprudencia era plenamente consciente de las diferencias entre ambas instituciones (en cuanto a sus presupuestos y, sobre todo, en cuanto a sus efectos) y de que la aplicación de la excepción de litispendencia a los casos de prejudicialidad era solo analógica. Por eso se hablaba en tales casos de litispendencia impropia.

La consecuencia fue que, promulgada la LEC de 2000, que dedica un precepto específico a regular las situaciones de prejudicialidad civil (art. 43), no tuviera sentido ya hablar de litispendencia impropia o, si se prefiere, que no fuera posible acudir a la excepción de litispendencia de los arts. 416 y 421 LEC para denunciar las situaciones de prejudicialidad civil, porque para hacer valer estas existen los cauces del art. 43 LEC: acumulación de autos y, si no es posible, suspensión del proceso o (si no concurren los requisitos para que proceda decretarla) decisión por el juez de la cuestión con eficacia solo prejudicial o a los solos efectos de la decisión de la cuestión principal (sin eficacia de cosa juzgada material). Y esto ha sido apreciado con claridad tanto por la «jurisprudencia menor» ${ }^{3}$ como por el $\mathrm{TS}^{4}$.

Así, la SAP Guadalajara, Sección 1.a , de 25 de septiembre de 2007 (JUR 2008/60090) que, después de precisar con claridad las diferencias conceptuales y la distinta eficacia de la litispendencia y la prejudicialidad civil, dice lo siguiente: «La parquedad legislativa en orden al tratamiento de las cuestiones prejudiciales no penales había llevado a la jurisprudencia a ensanchar de manera significativa el ámbito de la litispendencia, precisamente para englobar en ella las cuestiones prejudiciales civiles. La actual regulación en la Ley de Enjuiciamiento Civil, partiendo del mismo concepto y de los mismos efectos, distingue según el orden jurisdiccional al que pertenece la cuestión que se muestra en el proceso civil como prejudicial. Y cuando esa cuestión es también de orden civil, permite, a instancia de parte, la suspensión del proceso en tanto se resuelve la cuestión prejudicial ya deducida en otro proceso que no resulte acumulable a aquel en que la prejudicialidad se plantea. De ello deriva que la jurisprudencia anterior no resulte ya aplicable, al dotar la Ley de Enjuiciamiento Civil de efectos distintos a la litispendencia y a la prejudicialidad."

Y, con más rotundidad, el AAP Las Palmas, Sección 3. a, de 15 diciembre de 2006 (JUR 2007/143428), que precisa esta diferencia de efectos: «[...] la decisión del auto recurrido en apelación, como la propia alegación de excepción de litispendencia deducida por el actor principal-reconvenido, incurren en la confusión entre dos instituciones que la vigente LEC separa, la prejudicialidad civil del art. 43 LEC —antigua litispendencia prejudicial — y la litispendencia propiamente dicha, o basada en identidad de objeto del art. 416-2 y 421 de la misma ley. Bajo la vigente ley, la prejudicialidad determina suspensión del proceso y la litispendencia sobreseimiento de las actuaciones [...] Si analizamos el art. 421 de la LEC 1/00, se distingue el 
Mientras la litispendencia se vincula con el efecto negativo de la cosa juzgada («es una figura procesal cuya interpretación teleológica coincide plenamente con la de la cosa juzgada, que sirve de anticipo de aquella»), la prejudicialidad guarda relación con su efecto positivo. En efecto, la prejudicialidad civil puede provocar la paralización del segundo proceso civil en el estado en el que se halle hasta que se resuelva definitivamente el primero; $y$, si concurren

caso de la litispendencia propiamente dicha por coincidencia plena de objetos, que conduce al auto de sobreseimiento del proceso, del supuesto en que existe ya sentencia previa firme con efectos prejudiciales, en cuyo caso el art. 421-1-2. en relación con el art. 222 LEC conducen al rechazo de la excepción de litispendencia, y a la toma en consideración de la sentencia previa cuando se sentencia el segundo proceso. No regula, pues, la Ley en el art. 421 el caso de que esté todavía vivo por no existir sentencia firme otro proceso que tiene valor prejudicial en el presente. Y no lo regula en el art. 421 porque sí lo hace en el art. 43 LEC: Es decir, la litispendencia, actualmente, solo tiene encaje cuando existe coincidencia de objetos litigiosos. Cuando existe una sentencia ya firme con efectos prejudiciales, el juicio prosigue y el juzgador tendrá en cuenta dicha sentencia en la suya propia. Y cuando dicha sentencia prejudicial todavía no existe, lo que procede es la acumulación de procesos o la suspensión «a resultas» conforme al art. 43 LEC.»

Véase, con la misma doctrina, la AAP Madrid, Sección 9. a, de 17 de diciembre de 2010 (JUR 2011/77929).

4 A la distinción entre ambas instituciones se refiere, por ejemplo, la STS de 13 de octubre de 2010 (RJ 2010/7451) (en el mismo sentido, el ATS de 24 de mayo de 2005 [JUR 2006/220042] y la STS de 29 de diciembre de 2011 [RJ 2012/171]): «La jurisprudencia de esta Sala ha venido a perfilar la distinción entre litispendencia y prejudicialidad civil [...] que se produce, como ha dicho la STS de 22 de marzo de 2006 (RJ 2006/2315), cuando hay conexión entre el objeto de los dos procesos, de modo que lo que en uno de ellos se decida resulte antecedente lógico de la decisión de otro aun cuando no concurran todas las identidades que exigía el artículo 1252 del CC [actual art. 222 LEC] [... Sentado que no se trata de supuestos de litispendencia, por no reunirse los requisitos necesarios para ello, ha de considerarse acertada la afirmación de la Audiencia recurrida en el sentido de que no cabe solicitar tal suspensión una vez que ha finalizado la primera instancia por haberse dictado sentencia en la misma. Sin duda dicha sentencia ya habrá resuelto sobre el antecedente lógico de carácter civil que influye en la decisión del objeto del proceso y a partir de ese momento únicamente cabe ya la revisión de lo resuelto mediante los recursos ordinario y extraordinario. A ello contribuye también la propia posición adoptada por el legislador, a la que la Audiencia atribuye especial significación, en el sentido de que contra la resolución que acuerde la suspensión cabe recurso de apelación, lo que únicamente resulta comprensible si el pleito se encuentra en primera instancia». 
los requisitos del art. 222.4 LEC, el juez de aquel proceso (el segundo) quedará vinculado por lo decidido en este (el primero) ${ }^{5}$. En este caso, la cosa juzgada no opera como excluyente de una decisión sobre el fondo del asunto, sino que le sirve de base, y para que se produzca esa vinculación — ha afirmado la STS de 30 de mayo de 2005 (RJ 2005/4246) — «no es preciso que concurran todos los requisitos exigidos para que opere el efecto negativo o preclusivo de la res iudicata (STS de 1 de diciembre de 1997 [RJ 1997/8692]) $)^{6}$. Antes bien, basta con la identidad de personas ${ }^{7}$, cualesquiera que sean las posiciones que ocupen en cada uno de los procesos, y con que lo que se haya decidido en el anterior constituya un antecedente lógico de lo que sea objeto del posterior».

\section{LAS POSTURAS EXISTENTES EN LA JURISPRUDENCIA}

La Sentencia de la Audiencia Provincial (SAP) de Asturias, Sección 1. a, de 19 diciembre de 2014 (AC/2014/2138), abordó la cuestión en su fun-

5 Como dice la SAP Málaga, Sección 5. a, de 12 de noviembre de 2003 (JUR 2004/12793), ello «es consecuencia de que en la nueva LEC se regula por vez primera, también el efecto positivo de la cosa juzgada en el art. 222.4 [...] efecto de cosa juzgada que no se reconocía legalmente, pero sí en la jurisprudencia [...] según el cual en el segundo proceso el juzgador queda vinculado a lo ya juzgado cuando tiene que decidir sobre una relación o situación jurídica de la que la sentencia anterior es condicionante o prejudicial».

6 En efecto, no se cuestiona la inexigibilidad de la identidad objetiva. Como recuerdan las SSTS de 25 de mayo de 2010 (RJ 2010/3719) y 15 de octubre de 2012 (JUR 2012/341436), el hecho de que los objetos de dos procesos difieran o no sean plenamente coincidentes no es óbice para extender al segundo pleito lo resuelto en el primero respecto a cuestiones o puntos concretos controvertidos que constan como debatidos, aunque tan solo con carácter prejudicial, y no impide que el órgano judicial del segundo pleito decida sin sujeción en todo lo restante que constituye la litis

7 No obstante, se discute si la vinculación a lo resuelto por el juez que decide la cuestión prejudicial se produce solo en los casos en que concurra el requisito de la identidad subjetiva entre procesos o también en los demás. La STS 527/2013, de 3 de septiembre (RJ 2013/5926), desvincula la eficacia de la resolución prejudicial civil del instituto de la cosa juzgada y admite a estos efectos (de la vinculación) la subsistencia de la figura de la litispendencia impropia. En mi opinión, la incorporación a la LEC/2000 de su art. 43 pone de manifiesto la voluntad del legislador de separar ambas figuras (litispendencia y prejudicialidad; y cuando se plantea esta última, en defecto de previsión legal sobre la vinculación, habrá que estar a los criterios generales, conforme a los cuales: 1) solo existirá vinculación a la decisión si concurren los requisitos del art. 222.4 LEC; y 2) ello no es óbice para que el juez del segundo proceso esté vinculado a la declaración de hechos probados del primer proceso. 
damento de derecho segundo y expuso las posturas entonces existentes en la jurisprudencia menor: «Pues bien, debe señalarse que distintas han sido las resoluciones judiciales decidiendo esta primera excepción, unas acordando la suspensión del correspondiente procedimiento en tanto se resuelve el del Juzgado de Madrid, unas segundas apreciando no prejudicialidad, sino litispendencia, lo que lleva al archivo de los procedimientos y, por último, unas terceras que han rechazado tanto una como la otra medida». Veámoslas:

a) Unas sentencias de audiencias, apreciando la prejudicialidad civil, acordaron la suspensión de los procedimientos en que se ejercitaba la acción individual en tanto que se resolvía el proceso en que había ejercitado la acción colectiva. La pretensión, a juicio de tales resoluciones, es la misma en ambos procesos; es decir, la nulidad de la cláusula y, en su caso, el reintegro de las cantidades indebidamente cobradas a consecuencia de dicha cláusula. $\mathrm{Y}$ estas identidades

[...] determinan un claro supuesto de litispendencia impropia o por conexión o prejudicialidad civil, pese a no concurrir la triple identidad, y ello porque resulta condicionada la estimación de la presente demanda (acción individual) por lo que resuelva el procedimiento de Madrid (acción colectiva) nacido con anterioridad, que se constituye en antecedente lógico y necesario para resolver acerca del objeto principal de este.

Acogen, por tanto, la tesis de la STS 527/2013, de 3 de septiembre, que antes veíamos, conforme a la cual no es necesario que concurra el requisito de la identidad subjetiva del art. 222.4 LEC para que opere el efecto vinculante.

Otras sentencias, en cambio, rechazan la prejudicialidad civil, aunque con argumentos diversos. La SAP Granada, Sección 3. a, de 23 de mayo de 2014 (AC 2014/1686), diferencia la acción individual y la colectiva, y señala el distinto control realizado en uno y otro caso, ya que «mientras en la colectiva se lleva a cabo un control abstracto de validez atendiendo lo que puede entenderse como un consumidor medio y las características de las pautas estandarizadas de la contratación en masa, en la individual el análisis parte de las circunstancias concretas del caso en particular y de la posición individual del consumidor accionante», y concluye que no existe interferencia entre una y otra acción.

En la misma línea, el Auto de la Audiencia Provincial (AAP) de Alicante, Sección 8. a, de 31 de marzo de 2014 (JUR 2014/116992), señala que... 
[...] los intereses en juego en cada una de las acciones son distintos [...] tanto más cuanto, como es el caso, no consta ni que los demandantes formen parte del elenco de los concretos intereses defendidos en el otro proceso, ni tan siquiera que hayan sido llamados a este proceso lo que, en todo caso, no puede constituirse ni en obligación ni en carga procesal con consecuencias negativas frente a su derecho individual a la tutela judicial efectiva.

Y el AAP Huelva, de 24 de febrero de 2014 (JUR 2014/122230), concluye lo siguiente:

[...] aunque se pudiese admitir una posible influencia de aquel procedimiento (en referencia al de Madrid en que se ejercitaban acciones colectivas) en éste solo para el supuesto de que aquél se resolviese favorablemente a los demandantes, incluso en ese supuesto no se podría estimar la prejudicialidad civil por cuanto [...] la jurisprudencia entiende que para que la suspensión pueda ser acordada correctamente es necesario que el objeto y decisión del otro litigio constituya el antecedente lógico y necesario para la resolución del segundo proceso.

b) Aunque en menor número, algunas sentencias acogieron la excepción de litispendencia en sentido propio (es decir, como una institución preventiva de la cosa juzgada), de modo que la consecuencia ya no era la suspensión del procedimiento en que se ejercitaba la acción individual de conformidad con el art. 43 de la LEC, sino, de acuerdo con el art. 421. 1 del mismo texto legal, su sobreseimiento. En apoyo de tal postura, el AAP Asturias cita el AAP Barcelona, Sección 15. a de 9 de octubre de 2014 (JUR 2014/283476) que, después de afirmar que nuestro ordenamiento optó por «un sistema de afectación personal de lo resuelto en la acción colectiva a todos los integrantes del grupo, esto es a todos los afectados, tanto en el caso de que lo resuelto sea favorable como adverso", señala que no se ha regulado en la ley procesal española el derecho de auto-exclusión del grupo, «de manera que los derechos de los afectados podemos considerar que se limitan a los que resultan del art. 15 LEC, esto es, intervenir en el proceso, o bien solicitar la acumulación de la acción individual a la colectiva (siempre que se cumplan los requisitos que exige el art. 76.2.1. ${ }^{\circ} \mathrm{LEC}$ ), o interesar la extensión de los efectos del pronunciamiento en fase de ejecución (art. 519 LEC)». Entiende también dicho auto que de ello se sigue que los particulares «tienen absolutamente vedado iniciar con posterioridad a la acción colectiva acciones de carácter individual que versen sobre el mismo objeto, ya que cosa juzgada y litispendencia no son más que dos aspectos de una misma cuestión separados por una perspectiva temporal». Y, desde el momento en que en el procedimiento de Madrid se ejercitan, como en el caso presente, la acción de nulidad y la de restitución de 
cantidades, la consecuencia respecto a ambas es la litispendencia y no meramente la de prejudicialidad civil.

Esta postura — minoritaria — parte de la identidad entre ambos procesos (colectivo e individual), incluso en los casos en que no exista identidad subjetiva, porque el art. 222.3 LEC prevé la extensión de los efectos de la cosa juzga$\mathrm{da}$ (y los preventivos de la litispendencia) «a los sujetos, no litigantes, titulares de los derechos que fundamenten la legitimación de las partes conforme a lo previsto en el art. 11 de esta Ley».

\section{LA STJUE DE 14 DE ABRIL DE 2016}

Esta sentencia (asuntos acumulados C 381/14 — Jorge Sales Sinués vs. Caixabank S. A.— y C 385/14 — Youssouf Drame Ba vs. Catalunya Caixa S. A.) resuelve las dos peticiones de decisión prejudicial planteadas por el Juzgado de lo Mercantil núm. 9 de Barcelona, mediante autos de 27 de junio de 2014, sobre la compatibilidad con el art. 7 de la Directiva 93/13 CEE de la normativa española relativa a la prejudicialidad civil (art. 43 LEC); y, en concreto, acerca de la compatibilidad con ese mismo artículo de la directiva de la suspensión de las acciones individuales hasta que recaiga sentencia firme que ponga fin a un procedimiento colectivo incoado por una asociación de consumidores y usuarios ${ }^{8}$.

En la sentencia se analiza básicamente la relación entre la acción colectiva de cesación de condiciones generales contractuales abusivas y la acción individual de nulidad de un contrato de préstamo hipotecario basada en que dicho contrato contiene una cláusula de esas características (abusiva). El abogado general, en su dictamen, se había pronunciado a favor de la distinción

$8 \quad$ Las cuestiones planteadas por el juzgado fueron las siguientes: 1) ¿puede considerarse (la prejudicialidad civil) un medio o mecanismo eficaz conforme al art. 7.1 de la Directiva 93/13/CE? 2) ¿Hasta qué punto ese efecto suspensivo supone un obstáculo para el consumidor y, por tanto, una infracción del art. 7.1 de la citada directiva a la hora de denunciar la nulidad de aquellas cláusulas abusivas incorporadas a su contrato? 3) El hecho de que el consumidor no pueda desvincularse de la acción colectiva, ¿supone una infracción del art. 7.3 de la Directiva 93/13/CE? 4) ¿ O, por el contrario, el efecto suspensivo del art. 43 LEC es ajustado al art. 7 de la Directiva 93/13/CE[E] al entender que los derechos del consumidor están plenamente salvaguardados por esa acción colectiva, arbitrando el ordenamiento jurídico español otros mecanismos procesales igualmente eficaces para la tutela de sus derechos y por un principio de seguridad jurídica? 
entre ambas: «[...] se trata de acciones de diferente naturaleza con un objeto parcialmente coincidente», ya que

[...] mientras que en la acción colectiva de cesación las partes tienen la posibilidad de formular sus observaciones sin que puedan valorarse todas las circunstancias de cada caso concreto (control abstracto y general), en la acción individual el juez debe tener en cuenta todas las circunstancias concurrentes en la fecha en la que se suscribió el contrato de préstamo, incluyendo su evolución, todas las circunstancias que concurran en su celebración, así como todas las demás cláusulas del contrato.

Y la posterior sentencia llega a la misma conclusión: «[...] las acciones individuales y colectivas tienen, en el marco de la Directiva 93/13, objetos y efectos jurídicos diferentes (como también lo es el control que con ellas se realiza del carácter abusivo de las cláusulas: abstracto en las primeras y concreto en las segundas)»; de modo que «la relación de índole procesal entre la tramitación de las unas y de las otras únicamente puede atender a exigencias de carácter procesal asociadas, en particular, a la recta administración de la justicia y que respondan a la necesidad de evitar resoluciones judiciales contradictorias».

Por ello, es claro para la sentencia que la acción colectiva y la acción individual son independientes, por lo que la sentencia dictada en el proceso en que se conoce de la primera no producirá eficacia de cosa juzgada — ni previamente litispendencia - en un posterior proceso en que se ejercite la segunda (acción individual). Como afirma el abogado general, deberá admitirse que «un consumidor que decide ejercitar una acción individual no debería verse directamente afectado por la sentencia dictada en el procedimiento colectivo, aunque evidentemente el tribunal que conozca de la acción individual tendrá en cuenta dicha sentencia». Por eso, la posibilidad de que el consumidor intervenga en la acción colectiva no puede asimilarse al ejercicio de una acción individual. Tal asimilación implicaría para ese consumidor afectado, entre otras consecuencias, la renuncia a su fuero propio (el de su domicilio) y quedar supeditado a la manera en que la asociación de consumidores haya abordado el asunto, sin poder modificar el objeto o introducir otras pretensiones.

La conclusión no es tan tajante con respecto a la prejudicialidad. Entiende la sentencia que resulta contraria al principio de efectividad consagrado en la Directiva 93/13 una interpretación de la normativa procesal controvertida (art. 43 LEC) que considere que existe la obligación de suspender la acción individual cuando exista un procedimiento colectivo paralelo o que conceda una prioridad automática a la acción colectiva respecto de las acciones 
individuales sin que el consumidor pueda decidir, por un lado, no ejercitar su derecho o ejercitarlo eficazmente en el marco de un procedimiento individual, ni, por otro lado, desvincularse de la acción colectiva'. Dicho con otras palabras, entiende la sentencia que el consumidor «debería poder retirarse [de la acción colectiva] en cualquier momento antes de que se dicte la resolución definitiva o de que el asunto se resuelva válidamente de otra manera [...] sin que se le prive de la posibilidad de proseguir con su demanda de otra forma, si ello no perjudica a la buena administración de la justicia».

Por consiguiente, como en nuestro ordenamiento el art. 43 LEC no impone al juez que conoce de la acción individual la suspensión del proceso hasta que se resuelva el proceso en que se ejercitó la colectiva y prevé alternativas (por ejemplo, la decisión por el juez de la cuestión prejudicial incidenter tantum), habrá que entender que existe un margen para que pueda operar la prejudicialidad siempre que se reconozca el derecho del consumidor afectado a desvincularse de la acción colectiva.

9 La conclusión de la sentencia, en efecto, es clara: «El art. 7 de la Directiva 93/13/ CEE del Consejo, de 5 de abril de 1993, sobre las cláusulas abusivas en los contratos celebrados con consumidores, debe interpretarse en el sentido de que se opone a una normativa nacional, como la de los litigios principales, que obliga al juez que conoce de una acción individual de un consumidor, dirigida a que se declare el carácter abusivo de una cláusula de un contrato que le une a un profesional, a suspender automáticamente la tramitación de esa acción en espera de que exista sentencia firme en relación con una acción colectiva que se encuentra pendiente, ejercitada por una asociación de consumidores de conformidad con el apartado segundo del citado art. con el fin de que cese el uso, en contratos del mismo tipo, de cláusulas análogas a aquella contra la que se dirige dicha acción individual, sin que pueda tomarse en consideración si es pertinente esa suspensión desde la perspectiva de la protección del consumidor que presentó una demanda judicial individual ante el juez y sin que ese consumidor pueda decidir desvincularse de la acción colectiva.»

En este mismo sentido había concluido el abogado general que «[...] habida cuenta del principio de efectividad, el art. 7 de la Directiva 93/13 debe interpretarse en el sentido de que no se opone a una normativa procesal nacional, como la controvertida en los litigios principales, que permite decretar, debido a la prejudicialidad civil, la suspensión de una acción individual incoada paralelamente a una acción colectiva de cesación hasta que recaiga sentencia firme que ponga fin al procedimiento colectivo, a condición de que, por un lado, tal suspensión no sea obligatoria ni automática, y, por otro lado, el consumidor afectado pueda desvincularse de la acción colectiva.» 


\section{LA STC 148/2016, DE 19 DE SEPTIEMBRE ${ }^{10}$}

Esta sentencia llega a la misma conclusión que la sentencia del Tribunal de Justicia de la Unión Europea (TJUE), pero desde la perspectiva constitucional.

En la demanda se había invocado la vulneración del derecho de acceso a la jurisdicción de los recurrentes por el AAP Barcelona, Sección 15. a , de 9 de octubre de 2014 (JUR 2014/283476), citado anteriormente, que —en el supuesto que estamos analizando (inicio de un proceso ejercitando la acción individual cuando estaba pendiente el proceso en que se había ejercitado una acción colectiva) — había estimado la excepción de litispendencia; si bien el TC consideró que, aun no habiendo sido recurrida expresamente en amparo la resolución del Juzgado de Primera Instancia que había acordado no la litispendencia, sino la suspensión del proceso por prejudicialidad, el recurso debía entenderse interpuesto también frente a ella ${ }^{11}$.

Para el TC «un examen prima facie de las normas que regulan en nuestro ordenamiento, de manera por cierto algo dispersa, la llamada acción colectiva de cesación de cláusulas contractuales, no permite sustentar la tesis del desplazamiento o exclusión de la acción individual de nulidad de cláusulas abusivas, en beneficio de la referida acción de cesación». Y ello por las siguientes razones:

1. a) No existe una identidad subjetiva en ambos procesos. En primer lugar, porque el art. 15.4 LEC

[...] dispensa de adoptar las medidas de llamamiento y publicidad del proceso en todas las modalidades de acción de cesación, con desaparición, así, de toda posible carga procesal del reclamante individual por tener que acudir al proceso de cesación. Por ello, no tenían que atender al emplazamiento efectuado, ni en ese ni en otro proceso de cesación en cualquier parte del territorio nacional, por más que apareciere impugnada una cláusula del mismo contenido que la suya, ni antes ni después de

10 La doctrina establecida en esta sentencia ha sido asumida por sentencias posteriores: SSTC núms. 206 a 209 y 218, 221 y 223, todas de 2016; y SSTC núms. 3 y 4 de 2017.

11 La sentencia se apoyó para ello en la doctrina del TC que considera que la demanda de amparo "constituye un todo unitario, cuya lectura ha de acometerse con un criterio flexible y no formalista, importando sobre todo que el escrito permita conocer la vulneración constitucional denunciada y la pretensión deducida» (STC 123/2010, de 29 de noviembre [FJ 2]5). 
formalizar demanda individual de nulidad de su cláusula y solicitud de devolución de lo pagado por ella.

Tiene razón la sentencia cuando dice que la norma del art. 15.4 dispensa del deber de notificar en el caso de las acciones colectivas de cesación, por lo que el consumidor no necesita estar presente en las actuaciones del proceso en el que se ejercita la acción colectiva y puede actuar al margen de él ejercitando la acción individual en un posterior proceso. Esta es la interpretación literal del precepto. Sin embargo, se plantean, por lo menos, estas dos dudas: si compete al TC realizar la interpretación del precepto - porque parece fuera de duda que plantea una cuestión de mera legalidad ordinaria- y, sobre todo, si esa interpretación, prevista para cuando se ejercita la acción colectiva de cesación, debe mantenerse cuando a ella se acumula la acción reparadora o indemnizatoria. Para la sentencia es claro que sí. En sentido crítico se ha pronunciado un sector importante de la doctrina ${ }^{12}$. En mi opinión, la cuestión es dudosa. Esta interpretación del precepto (en relación con los artículos 222.3 y 221.2-1. . LEC) supone cerrar en estos casos el proceso a los consumidores afectados, por lo que entiendo que la cuestión tiene relevancia constitucional y el TC debió, o bien realizar una interpretación del precepto conforme a la $\mathrm{CE}$, cosa que no hizo, o bien plantear la cuestión interna de inconstitucionalidad prevista en el art. 55.2 LOTC.

Por lo demás, las disposiciones reguladoras de ese proceso colectivo (Ley de Condiciones Generales de la Contratación y texto refundido de la Ley General para la Defensa de los Consumidores y Usuarios) no prevén, siquiera, la legitimación de afectados individuales, aunque estos podrían confiar su caso a alguna de las entidades legitimadas como pretensión acumulada, lo cual no sucedió en el caso resuelto por la sentencia.

En consecuencia, si los aquí recurrentes no eran parte en ese proceso de acción colectiva, ni estamos en un supuesto de legitimación indirecta impuesta ex lege (como en el ámbito de la defensa colectiva de los derechos de propiedad intelectual y las entidades de gestión especializadas: SSTC 196/2009, de 28 de septiembre, y 123/2010, de 29 de noviembre), la conclusión lógica es que falta la identidad del elemento subjetivo necesario entre ambos procesos, el de cesación y el individual, para poder acordar la litispendencia.

Aguilera Morales (2017) echa de menos un razonamiento del TC sobre la inaplicación al caso del art. 222.3 LEC, un precepto este que, en una interpretación literal, podría cuestionar la conclusión de que no existe identidad

12 Véase, por ejemplo, Carrasco Perera (2017). 
subjetiva entre ambas acciones. En mi opinión, sin embargo, no era procedente que lo hiciera porque realizar la interpretación de tal precepto, lo mismo que del art. 15.4 LEC, entra dentro del ámbito de actuación propio de los tribunales ordinarios.

2.a) Por otra parte, la identidad — que no mera similitud (cuando se trata de litispendencia) - de objeto entre ambos procesos «resulta cuando menos dudosa». La demanda de cesación se configura por ley como un instrumento de control abstracto de cláusulas ilícitas, y lo que se pretende con ella es que el profesional demandado deje de recomendarlas o suscribirlas con sus potenciales clientes. En este caso, la acción de cesación impugnaba, entre otras, la cláusula suelo, cuyo contenido coincide con la firmada por los recurrentes años antes con la misma entidad bancaria. Pero lo cierto es que en ese proceso no se conoció de la cláusula suelo de «su» contrato, ni de las circunstancias concurrentes en su celebración (arts. 4.1 de la Directiva 93/13/CEE y 82.3 del texto refundido de la Ley General para la Defensa de los Consumidores y Usuarios), como, por ejemplo, el cumplimiento del principio de transparencia. El objeto controvertido, por tanto, entre ambos procesos es similar, pero no idéntico.

Lo cual — dice la sentencia — no obsta a que el juzgado a quo, al dictar sentencia sobre el fondo, deba de tener en cuenta los pronunciamientos ante todo del TS, máximo intérprete de la legalidad ordinaria (art. $123 \mathrm{CE}$ ), en torno a la validez o nulidad de este tipo de cláusula.

3.a) Extender de manera automática un efecto de cosa juzgada derivado de la estimación de la acción de cesación a todas las cláusulas iguales insertas en la universalidad de contratos en vigor, además de no preverse en las normas que regulan dicha acción colectiva, puede llegar a atentar contra la autonomía de la voluntad del consumidor que no desee tal nulidad en su contrato, en los términos observados antes por nuestro TS y el TJUE. O cercenar las posibilidades de su impugnación individual si la demanda de cesación se desestima por mor de una línea de defensa jurídica de la entidad actora, distinta de la que hubiera sostenido el reclamante individual con base en las circunstancias concurrentes solo por él conocidas.

En definitiva, empleando palabras de la STC 106/2013, FJ 5, del «examen de las resoluciones impugnadas se desprende que los órganos judiciales han realizado una interpretación de la ley procesal, principalmente de los artículos mencionados, que, superando su tenor literal, han impedido a la parte recurrente obtener una resolución de fondo sobre determinadas pretensiones». En este caso, además, de modo contrario al derecho comunitario aplicable. 


\section{LA RECEPCIÓN DE LA DOCTRINA POR EL TRIBUNAL SUPREMO}

La precedente doctrina (del TJUE y del TC) ha sido asumida por el TS. De las ya numerosas sentencias en las que se recoge, tomaré la STS 486/2017, de 20 de julio (RJ 2017/3379) en la que se contiene un resumen que me parece suficiente a los efectos del presente trabajo.

Dice la sentencia:

En relación con la invocada eficacia de cosa juzgada material del pronunciamiento contenido en la sentencia 241/2013, de 9 de mayo, que limitaba el efecto restitutorio derivado de la nulidad de las cláusulas suelo enjuiciadas a la publicación de esa sentencia, hemos reiterado en estos últimos meses que no vincula a los procedimientos posteriores en los que se ejercitaba una acción individual por consumidores que no consta hubieran sido determinados individualmente en aquella sentencia. Así, en la sentencia 123/2017, de 24 de febrero, justificamos por qué de acuerdo con la jurisprudencia del Tribunal de Justicia (contenida en la STJUE de 14 de abril de 2016), la jurisprudencia del Tribunal Constitucional (contenida en la STC 148/2016, de 19 de septiembre, y otras posteriores) y la jurisprudencia de esta misma Sala Primera del Tribunal Supremo (STS 375/2010, de 17 de junio), entre las acciones colectivas y acciones individuales no existe identidad objetiva, puesto que tienen objetos y efectos jurídicos diferentes, y por ello no cabe apreciar el efecto de cosa juzgada material. De tal forma que, como concluimos en la sentencia $357 / 2017$, de 6 de junio, «en relación con los consumidores que no se personaron en el procedimiento en que se ejercitó la acción colectiva, [...] el llamamiento que se les hace conforme al art. 15 de la Ley de Enjuiciamiento Civil no es suficiente para justificar la extensión frente a ellos de la eficacia de cosa juzgada que establece el art. 222.3 de la misma Ley. Una interpretación conjunta de los arts. 15, 222.3 y 221 de la Ley de Enjuiciamiento Civil lleva a la conclusión de que la cosa juzgada de la sentencia estimatoria de la acción colectiva afectará únicamente a los consumidores no personados que estén determinados individualmente en la propia sentencia, conforme dispone el art. 221.1-1. ${ }^{a}$ de la Ley de Enjuiciamiento Civil.

\section{PRECISIONES A LA DOCTRINA PRECEDENTE: LA EFICACIA SECUNDUM EVENTUM LITIS DE LA SENTENCIA DICTADA EN EL PROCESO EN QUE SE EJERCITA LA ACCIÓN COLECTIVA. LA STS 367/2017, DE 8 DE JUNIO}

Ciertamente, como se afirma en la STS de 1 de julio de 2010 (RJ 2010/6554), la defensa de los intereses colectivos en el proceso civil no está configurada exclusivamente como un medio de resolución de conflictos inter- 
subjetivos de quienes participan en el pleito. Está presente un interés ajeno que exige la expulsión del sistema de las cláusulas declaradas nulas por sentencia firme sin necesidad de petición previa. A tal fin, con precedentes en el ámbito del proceso contencioso-administrativo cuando el objeto del proceso es una disposición general, es preciso superar las fronteras subjetivas que fija el art. 222.3 LEC ( «[1]a cosa juzgada afectará a las partes del proceso en que se dicte y a sus herederos y causahabientes, así como a los sujetos, no litigantes, titulares de los derechos que fundamenten la legitimación de las partes conforme a lo previsto en el art. 11 de esta Ley») y proyectar sus efectos ultra partes, como un instrumento para alcanzar el objetivo señalado en el art. 7.1 de la Directiva 93/13/CEE de que cese el uso de las cláusulas abusivas, y a tal efecto la regla $2 .^{\mathrm{a}}$ del art. 221.1 dispone que «[s] i como presupuesto de la condena o como pronunciamiento principal o único, se declara ilícita o no conforme a la ley una determinada actividad o conducta, la sentencia determinará si conforme a la legislación de protección de consumidores y usuarios la declaración ha de surtir efectos procesales no limitados a quienes hayan sido partes en el proceso correspondiente».

Sin embargo, recuerda la STS de 9 de mayo de 2013 (RJ 2013/3088), la proyección erga omnes exige tener en cuenta que la exposición de motivos de la LEC, al tratar de la tutela de intereses jurídicos colectivos llevados al proceso, afirma que "[e]n cuanto a la eficacia subjetiva de las sentencias, la diversidad de casos de protección impone evitar una errónea norma generalizadora».

$\mathrm{Al}$ respecto, la STS 367/2017, de 8 de junio (RJ 2017/2509) ${ }^{13}$, después de reconocer que la «eficacia ultra partes de las sentencias dictadas en los litigios en que se ejercitan estas acciones colectivas es problemática», distingue tres escenarios diferentes, según que se trate de a) los efectos de la sentencia dictada en un proceso en que se ejercita una acción colectiva de declaración de nulidad y cesación de una cláusula suelo abusiva en un posterior litigio en que se ejercitaba por otra asociación de consumidores una acción colectiva

13 En el caso por ella resuelto la entidad financiera, reconociendo que la cláusula suelo objeto de la acción individual era la misma que había sido objeto de la acción colectiva, alega que la sentencia que estimó la acción colectiva carece de trascendencia en la resolución de la acción individual, "por lo que la decisión a adoptar no debe venir determinada por lo que se resolvió en la sentencia sobre la acción colectiva, y que pese a que esta declaró la nulidad de tal cláusula suelo y acordó la cesación en su utilización, el presente recurso (de casación) debe ser desestimado y la sentencia de la Audiencia Provincial, que denegó la nulidad pretendida, debe ser confirmada». La entidad, por tanto, invocó la doctrina sobre la independencia de ambas acciones que ya se ha expuesto en el trabajo. 
respecto de la misma cláusula predispuesta por el mismo banco ${ }^{14}$; b) los efectos sobre el proceso en que se ejercita la acción individual de una sentencia desestimatoria de la acción colectiva, que constituye el supuesto analizado en las páginas anteriores, en el que se concluye que tales pronunciamientos desfavorables carecen de la eficacia de cosa juzgada; y $c$ ) los efectos que ha de tener la sentencia estimatoria de una acción colectiva en un posterior litigio en el que se ejercita una acción individual de nulidad.

Para este último caso, que es el supuesto resuelto por la sentencia, «debe tomarse en cuenta la función tuitiva de los consumidores que tiene la acción colectiva, que se funda en lo previsto en el art. 7 de la Directiva 93/13/CEE. Esta función se vería frustrada si el éxito de una acción colectiva careciera de cualquier trascendencia en procesos pendientes o futuros en que se ejercitara la acción individual respecto de dicha cláusula». Y a partir de ahí reconoce la eficacia de la sentencia estimatoria de la nulidad de la cláusula en el proceso en que se ejercita la acción individual (también de nulidad). La sentencia trae a colación la precedente STS de 25 de marzo de 2015 (RJ 2015/735), que abordó esta cuestión apelando a la doctrina comunitaria. En este ámbito —dice—, la sentencia del TJUE de 26 de abril de 2012 señaló que

[...] no se opone a que la cláusula abusiva que forma parte de las condiciones generales de los contratos celebrados con consumidores en el marco de una acción de cesación, contemplada en el artículo 7 de la Directiva, ejercitada contra un profesional por motivos de interés público y en nombre de los consumidores por una entidad designada por el Derecho Nacional, surta efectos, de conformidad con dicho Derecho, para cualquier consumidor que haya celebrado con el profesional de que se trate un contrato al cual le sean de aplicación las mismas condiciones generales, incluso para los consumidores que no hayan sido parte en el procedimiento de cesación.

Y — continúa la sentencia- los órganos jurisdiccionales nacionales que comprueben el carácter abusivo de una cláusula de las condiciones generales están obligados —en virtud del art. 6, apdo. 1, de la directiva- a aplicar todas las consecuencias que, según el derecho nacional, se deriven de ello para que el consumidor no resulte vinculado por dicha cláusula.

Con la Sentencia 367/2017 se pone de manifiesto tanto la dificultad del tema que estamos examinando como las dudas existentes a la hora de afrontar su solución. La doctrina en ella expuesta parece razonable, aunque no creo que pueda sustentarse en una pretendida eficacia de cosa juzgada en el proce-

14 Este supuesto fue el planteado en el proceso resuelto por la STS 705/2015, de 23 de diciembre (RJ 2015/5714), que estimó la eficacia de cosa juzgada material. 
so en que se ejercita la acción individual de la sentencia dictada en el proceso colectivo; la eficacia de cosa juzgada es absoluta, se produce o no se produce, pero no cabe sostener que, cuando la sentencia es apta para producirla, hay casos en los que debe excluirse ${ }^{15}$; y estos casos de excepción son expresamente admitidas por la sentencia. Por lo demás, en el caso de que se admita que existe cosa juzgada, habría que decir que la misma operaría secundum eventum litis, en contra del criterio defendido por un importante sector de la doctrina; aunque, ciertamente, hay autores que la admiten ${ }^{16} \mathrm{y}$ existen otros casos en nuestro ordenamiento en los que la eficacia de cosa juzgada se hace depender del sentido del fallo ${ }^{17}$.

La cuestión entonces es ver si, a la luz de la jurisprudencia tuitiva del TJUE, las categorías procesales tradicionales son aplicables a los procesos para la tutela de los derechos de los consumidores y, a la vista de lo expuesto, no me parece que la respuesta pueda ser siempre afirmativa.

\section{CONCLUSIONES CRÍTICAS}

1.a) La primera deriva de las consideraciones precedentes: si la acción colectiva y la acción individual son independientes, porque no existe identidad subjetiva entre ellas y es distinta su naturaleza y contenido y también el control que en una y otra se ejerce (abstracto y concreto, respectivamente), la sentencia (desestimatoria) dictada en el proceso en que se conoce de la primera (acción colectiva de cesación) no producirá eficacia de cosa juzgada —ni previamente litispendencia y tampoco prejudicialidad- en un posterior proceso en que se ejercite la segunda (acción individual de nulidad).

Sin duda, es esta una conclusión que supone abandonar la literalidad del art. 222.3 LEC y su concreción en el art. 221.2-1. ${ }^{\circ}$ cuando se trata de procesos para la defensa de los consumidores ${ }^{18}$. No me parece, en cambio, que

15 Una cuestión distinta, que no viene al caso, se plantea con las resoluciones a las que la ley priva de la eficacia de cosa juzgada; por ejemplo, las sentencias que ponen fin a los juicios sumarios (art. 447 LEC).

16 Por ejemplo, Cachón Cadenas y Reynal Quirol (2015) defienden la eficacia de cosa juzgada positiva de la sentencia que acoge la acción colectiva, pero no de la que la desestima.

17 Por ejemplo, es una doctrina jurisprudencial consolidada que, en los procesos en que se ejercita la acción por un comunero en interés de la comunidad, la sentencia favorezca a los demás comuneros, pero no los perjudique.

18 Un sector de la doctrina (y también algunas sentencias) defienden que, en estos supuestos, la cosa juzgada se extiende más allá de las concretas personas que in- 
sea atinada la observación, realizada por Aguilera Morales $(2017)^{19}$, de que «el art. 221.1. 2. ${ }^{a}$ LEC no contempla un supuesto de extensión de la cosa juzgada, sino que es, más propiamente, una regla específica referida a la eficacia jurídico-material característica de las sentencias anulatorias o, en otros términos, una regla relativa al alcance subjetivo del efecto constitutivo propio de esta clase de sentencias». En mi opinión, el reconocimiento del efecto (jurídico material) expansivo (erga omnes) de la cesación o de la declaración de nulidad — como, en general, el de las sentencias constitutivas- no precisa de un precepto legal de cobertura. La norma se refiere a la cosa juzgada. Una cuestión diferente es que las normas de la LEC no estén preparadas para recibir con facilidad la doctrina sobre las relaciones entre acción colectiva y acción individual para la tutela de los derechos de los consumidores establecida por el TJUE y deban ser objeto de interpretación, incluso de su conformidad a la $\mathrm{CE}$, tal y como antes decía.

2. a) Cuando la sentencia dictada en el proceso en que se ejercita la acción colectiva sea estimatoria se reconoce su eficacia en el proceso ulterior en que se hace valer una acción individual; aunque el TS admite excepciones a esta eficacia y, por ello, difícilmente puede defenderse que nos encontremos ante la eficacia de cosa juzgada.

3. a) Las conclusiones de la sentencia del TJUE que hemos visto supra contemplaban el supuesto de ejercicio de la acción de cesación (previa declaración del carácter abusivo de la cláusula). La pregunta es si la doctrina

tervinieron en el procedimiento, afectando también a quienes sean titulares de los derechos que fundamenten la legitimación de las partes conforme a lo dispuesto en el art. 11 LEC, de manera similar a lo que ocurre con las sentencias recaídas en los procesos de impugnación de acuerdos sociales, que afectan tanto a los socios intervinientes en aquel como a aquellos que no intervinieron. Este es el criterio, por ejemplo, de la SAP Madrid de 28 mayo de 2008 (JUR 2008/212676): «Dado que la sentencia que resuelva el litigio promovido en defensa de intereses colectivos o difusos por una asociación, entidad o grupo de los citados despliega efectos de cosa juzgada frente a todos los consumidores y usuarios que resulten afectados por dichos intereses, tanto en el caso de que se hubieran integrado en el litigio, como parte, como en el caso de que hayan permanecido completamente extraños a él, el legislador regula de forma especial la necesidad de dar publicidad a estos procesos, con el fin de que los afectados individuales puedan comparecer en los mismos como parte, por medio de la intervención del art. 13, con las especialidades del art. 15 de la Ley de Enjuiciamiento Civil».

19 La autora cita a Tapia Fernández (2000: 13) y a Planchadell Gargallo (2014: 214 y ss.). 
establecida sobre la independencia de la acción colectiva y la acción individual es aplicable también en los casos en que se ejercitan acciones reparadoras (que tienen por objeto la condena a devolver una cantidad de dinero, a reparar los daños o a indemnizar de perjuicios causados). Porque, como antes decía, es claro que las asociaciones de consumidores, con fundamento en la legitimación del art. 11, sin distinción alguna, pueden ejercitar pretensiones de condena dineraria ( $y$, en general, resarcitorias e indemnizatorias) con independencia de que los consumidores eventualmente beneficiados intervengan en el procedimiento y sean determinados (o determinables) o no (art. 221.1 LEC): en el primer caso, «la sentencia estimatoria determinará individualmente los consumidores y usuarios que, conforme a las leyes sobre su protección, han de entenderse beneficiados por la condena»; en el segundo, "establecerá los datos, características y requisitos necesarios para poder exigir el pago y, en su caso, instar la ejecución o intervenir en ella, si la instara la asociación demandante». Y con independencia también de la acción que corresponde a cada consumidor para la tutela de su derecho individual (art. 11.1 LEC). En tales casos - y en lo que ahora interesa - se plantea previamente un problema de litispendencia o cosa juzgada.

Conforme a la sentencia del TJUE, parece que hay que admitir que, ejercitada una acción colectiva reparadora, un consumidor individual pueda apartarse del proceso y ejercitar la acción individual sin que el proceso quede excluido por litispendencia o suspendido por prejudicialidad. Según las conclusiones del abogado general, la intervención de los consumidores individuales en la acción colectiva (en el lado activo como demandantes o apoyando a la asociación demandante) no puede asimilarse al ejercicio de una acción individual; de ello derivaría que la sentencia que se dicte no producirá frente a ellos eficacia de cosa juzgada ${ }^{20}$.

En mi opinión, sin embargo, esa sentencia sí afecta a los consumidores personados en el procedimiento, consumiendo su acción individual, de forma que si, al amparo de lo dispuesto en el art. 11.1 LEC, un consumidor (persona-

20 De modo semejante, se pronuncia la sentencia dictada en primera instancia en el caso ADICAE al que hice referencia al comienzo de este trabajo: «Puesto que, como señalábamos en el fundamento jurídico cuarto, los consumidores y usuarios personados en el presente procedimiento no han ejercitado pretensiones propias, sino que intervienen como meros coadyuvantes de las acciones colectivas ejercitadas por la asociación de consumidores y usuarios demandante, motivo por el cual no procede efectuar el pronunciamiento del art. 221.1-3. ${ }^{\circ}$ LEC ("Si se hubieren personado consumidores o usuarios determinados, la sentencia habrá de pronunciarse expresamente sobre sus pretensiones")». 
do en el proceso en que se ejercitó la acción colectiva) ejercitara posteriormente la acción individual, operarían las excepciones de litispendencia o de cosa juzgada porque en el primer proceso (acción colectiva reparadora) se debatió - $\mathrm{O}$ pudo debatirse - plenamente la existencia del referido derecho y en él se prestó - o debió prestarse- audiencia al consumidor personado en el primer proceso (acción colectiva) y demandante en el segundo (acción individual), que, por tanto, pudo hacer valer sus derechos sin limitación alguna. Entiendo que la intervención de los consumidores afectados al amparo de la publicidad prevista en el art. 15 LEC se hace "para que hagan valer su derecho o interés individual» (art. 15.1). La eficacia de cosa juzgada se excluirá, en cambio, conforme a la doctrina de la sentencia, en los casos en que la acción individual sea ejercitada por un consumidor no personado en el proceso en que se ejercitó la acción colectiva.

Esta conclusión solo sería discutible en el caso de que la intervención del consumidor en el proceso iniciado por la acción colectiva reparadora no pueda asimilarse al ejercicio de una acción individual. Y así lo entendió el abogado general del TJUE en la sentencia analizada supra. En su opinión (ya lo veíamos antes), tal asimilación implicaría para el consumidor afectado, entre otras consecuencias, la renuncia a su fuero propio (el de su domicilio) y quedar supeditado a la manera en que la asociación de consumidores haya abordado el asunto, sin poder modificar el objeto o introducir otras pretensiones. Sin embargo, reitero mi opinión de que la intervención de los consumidores afectados al amparo de la publicidad prevista en el art. 15 LEC se hace "para que hagan valer su derecho o interés individual» (art. 15.1) y se somete al régimen del art. 13 LEC, cuyo apdo. tercero dispone lo siguiente:

Admitida la intervención [...] el interviniente será considerado parte en el proceso a todos los efectos y podrá defender las pretensiones formuladas por su litisconsorte o las que el propio interviniente formule, si tuviere oportunidad procesal para ello, aunque su litisconsorte renuncie, se allane, desista o se aparte del procedimiento por cualquier otra causa.

El problema se plantea a la hora de ver en qué forma afecta dicha sentencia a los consumidores posibles afectados para los que también se pidió la tutela por la asociación demandante que ejercitó la acción colectiva y no se encuentran personados en el procedimiento ${ }^{21}$. $\mathrm{Al}$ respecto, pueden realizarse las siguientes consideraciones:

21 Esta cuestión ha sido estudiada por la STS de 17 de junio de 2010 (RJ 2010/5407), a la que antes hacía referencia que señala lo siguiente: «El alcance de los efectos de la cosa juzgada cuando se trata del ejercicio de acciones colectivas plantea cuestiones de difícil resolución, pues, por una parte, es necesario garantizar el principio de esta- 
1. a) Si conforme al art. 222.3 LEC, la cosa juzgada afectará también «a los sujetos, no litigantes, titulares de los derechos que fundamenten la legitimación de las partes conforme a lo previsto en el art. 11 de esta Ley», sin distinguir si se integraron en el litigio como parte o permanecieron completamente extraños a él, adquiere especial relevancia la publicidad que el legislador da a estos procesos (art. 15 LEC), con el fin de que los afectados individuales puedan comparecer en los mismos como parte. Obsérvese que de tal obligación de publicidad solo quedan exceptuados «los procesos iniciados mediante el ejercicio de una acción de cesación para la defensa de los intereses colectivos y de los intereses difusos de los consumidores y usuarios» (art. 15.4 LEC), lo que es lógico puesto que las mismas vinculan solamente al empresario infractor y el efecto de la sentencia sobre los consumidores es meramente reflejo y no los impide posteriormente plantear acciones resarcitorias individuales. Pero, como dice la SAP Sevilla, Sección 5. a, de 22 enero 2004 (AC 2004/406), si lo que se plantea es una acción resarcitoria colectiva, exclusivamente o en unión con una acción de cesación (o de declaración de nulidad), la publicidad prescrita en el art. 15 constituye una garantía esencial del derecho a la tutela judicial efectiva de los perjudicados sin la cual no es posible dictar una resolución que los afecte. Ya me refería a ello anteriormente, al poner de manifiesto que el art. 15.4 LEC no debe aplicarse cuando a la acción de cesación se acumula otra resarcitoria, para cuyo ejercicio está legitimada también la asociación de consumidores de que se trate.

Sin embargo, me parece que, de la puesta en relación de ambos preceptos (arts. 222.3 y 15 LEC), no puede concluirse sin más que los consumidores a los que se les dio la oportunidad de comparecer y no se personaron en el proceso en que se ejercitó la acción colectiva han de estar a lo resuelto en la sentencia que en él se dicte por tener para ellos, en todo caso, eficacia de cosa juzgada; ni siquiera considero que sea aceptable aplicar la doctrina jurisprudencial sobre la legitimación del comunero, defendiendo que esta eficacia (de cosa juzgada) la produce la sentencia secundum eventum litis; es decir, solo

bilidad de las resoluciones judiciales y de seguridad jurídica, en que tiene su asiento esta institución, y, por otra, resulta evidente el propósito del legislador de que el reconocimiento de nuevas formas de legitimación para el ejercicio de estas acciones no suponga una restricción a la protección de los derechos de los consumidores. De esto se sigue que la consideración de los requisitos exigidos tradicionalmente por esta Sala para la consideración de la cosa juzgada, especialmente el de identidad subjetiva, no resuelve de forma automática la cuestión, para la que caben diversas soluciones legislativas, por lo que es necesario examinar cuál es el régimen que la LEC establece en esta materia.» 
cuando es favorable, dejando abierta la puerta para que puedan ejercitar la acción individual en el caso de que sea desfavorable.

2.a) Cuando la acción colectiva reparadora se ejercite para la tutela de los derechos o intereses de un grupo de consumidores determinado o fácilmente determinable, habrá que tener en cuenta (en lo que ahora interesa), además del llamamiento genérico publicando la admisión de la demanda en medios de comunicación, revisto en el art. 15.1 LEC, las normas siguientes: por un lado, el art. 15.2 LEC, que impone al demandante la comunicación previa de su propósito de presentación de la demanda a todos los interesados, a los que se reconoce la facultad de intervenir en el proceso en cualquier momento; y, por otro, el art. 221.1-1. a, conforme al cual «la sentencia estimatoria determinará individualmente los consumidores y usuarios que, conforme a las leyes sobre su protección, han de entenderse beneficiados por la condena».

En el caso de que las acciones se ejerciten para la tutela de un grupo de consumidores indeterminado o de difícil determinación, además del art. 15.1, los preceptos que se han de valorar serán los siguientes: el art. 15.3 LEC, conforme al cual el llamamiento de los consumidores afectados se realizará publicando la admisión de la demanda en medios de comunicación, suspendiéndose el curso del proceso y reanudándose con la intervención de todos aquellos consumidores que hayan acudido al llamamiento, no admitiéndose la personación individual de consumidores o usuarios en un momento posterior, sin perjuicio de que estos puedan hacer valer sus derechos o intereses conforme a lo dispuesto en los artículos 221 y 519 de esta ley; y el art. 221.1-1. a , II, conforme al cual la sentencia estimatoria «establecerá los datos, características y requisitos necesarios para poder exigir el pago y, en su caso, instar la ejecución o intervenir en ella, si la instara la asociación demandante».

En ocasiones, como ha señalado Armenta Deu (2014), se pueden plantear problemas a la hora de determinar si estamos en un caso u otro (tutela de intereses colectivos o difusos) ${ }^{22}$; pero en ambos casos se aplicará la norma

22 Con la SAP A Coruña de 23 de junio de 2005 (JUR 2009/203310), habría que preguntarse si la existencia de una pluralidad de afectados es sinónima de interés difuso, a los efectos de dispensar a la entidad actora de la obligación de cumplir las exigencias normativas de individualizar el grupo y efectuar las comunicaciones que, como presupuesto de la acción, exige el art. 15.2 de la LEC. Y, en el caso de responder negativamente, si no será aplicable la consecuencia prevista en la misma sentencia: «[...] al no haberse procedido de tal forma, hemos de compartir el criterio de la sentencia apelada, en cuanto limita la legitimación de la entidad recurrente a la defensa de los intereses de los 63 asociados a los que representa, para lo que se encuentra habilitada legalmente». Y con 
del art. 221.1-2..$^{\mathrm{a}} \mathrm{LEC}$ : «Si, como presupuesto de la condena o como pronunciamiento principal o único, se declarara ilícita o no conforme a la ley una determinada actividad o conducta, la sentencia determinará si, conforme a la legislación de protección a los consumidores y usuarios, la declaración ha de surtir efectos procesales no limitados a quienes hayan sido partes en el proceso correspondiente».

a) Cuando se ejercitan acciones para la tutela de intereses colectivos en sentido estricto (consumidores determinados o fácilmente determinables), podría sostenerse —dice la STS de 17 de junio de 2010 (RJ 2010/5407)— que, tras el llamamiento al proceso que se ordena hacer a quienes tengan la condición de perjudicados por haber sido consumidores del producto o usuarios del servicio que dio origen al proceso, para que hagan valer su derecho o interés individual (art. 15.1), la sentencia produce efectos de cosa juzgada respecto de todos ellos, «puesto que no se establece, a diferencia de lo que ocurre en el caso de perjudicados indeterminados (art. 15.3 LEC), que, aunque no se personen, podrán hacer valer sus derechos o intereses conforme a lo dispuesto en los arts. 221 y 519 de esta Ley».

Dispone el art. 221.1-1. ${ }^{a}$ que la sentencia «determinará individualmente los consumidores y usuarios que, conforme a las leyes sobre su protección, han de entenderse beneficiados por la condena», siendo estos los que se verán vinculados por la eficacia de cosa juzgada; no se olvide que, por definición, los consumidores afectados están determinados o son fácilmente determinables y, además del régimen de publicidad del art. 15.1, a todos ellos habrá debido comunicarse la demanda, por lo que difícilmente podrán alegar desconocimiento del proceso. Si se personan, la eficacia de cosa juzgada se extenderá a ellos en un eventual proceso ulterior en que ejerciten la acción individual (por ejemplo, buscando mejorar la cuantía obtenida). Si, a pesar del régimen de publicidad, no se personan, que los alcance la litispendencia del proceso anterior o la eficacia de cosa juzgada de la sentencia en él dictada dependerá

la SAP Sevilla, Sección 5. a de 22 de enero de 2004 (AC 2004/406) habría que sostener que no es posible admitir la pretensión de tutela de intereses o derechos difusos «[...] mientras que no se realice el esfuerzo preciso para tratar de identificar al colectivo afectado; pero aun cuando hipotéticamente tras ese esfuerzo quedaran perjudicados que no hubiesen podido ser localizados, el hecho de que no sea posible identificar exactamente o en su totalidad, o localizar, a los afectados no releva a las asociaciones de consumidores de identificar a los pertenecientes a su asociación que reúnen tal cualidad y además de comunicar previamente la demanda a todos aquellos afectados que puedan identificarse, esfuerzo que ni siquiera se ha intentado en el caso de autos». 
de que, a pesar de su no personación, hayan quedado determinados (o no) individualmente en la sentencia.

b) Cuando, por el contrario, los consumidores sean indeterminados, la sentencia no produce eficacia de cosa juzgada frente a los no personados. El régimen de publicidad previsto en tales casos (art. 15.3 LEC) establece que, aunque no se personen, podrán hacer valer sus derechos o intereses conforme a lo dispuesto en los arts. 221 y 519 de esta ley. Esto significa que, si se personan, tendrán la consideración de perjudicados y los afectará la cosa juzgada; por eso,

[...] la conclusión no es otra que la facultad de personación individual o colectiva de los afectados, en cualquier momento del procedimiento, a quienes se les puede reconocer individual y colectivamente su derecho en la sentencia dictada, si fueron parte del mismo antes de producirse dicha resolución definitiva; pero, una vez dictada, para obtener la condición de beneficiarios, es necesario que ésta adquiera firmeza, instando su reconocimiento y ejecución al amparo de los artículos 517, 519, 538 y siguientes de la LEC (SAP Madrid, Sección 12.a, de 17 de mayo de 2006 [JUR 2006/187882]).

Lo que parece indicar que, si no instan por lo menos su reconocimiento y en el incidente correspondiente no obtienen una resolución favorable, no tendrán la consideración de beneficiarios por la sentencia, que no les afectará, lo que dejará abierto el camino para la acción individual.

\section{Bibliografía}

Aguilera Morales, M. (2017), Articulación procesal de acciones individuales y colectivas en defensa de los consumidores a la luz del derecho de la Unión. Civitas. Revista Española de Derecho Europeo, 63, 111-127.

Armenta Deu, T. (2014). Cosa juzgada y acciones colectivas en el ordenamiento procesal civil español. En E. Carbonel (dir.) y R. Cabrera (coord.). Intereses colectivos y legitimación activa (pp. 163-186). Cizur Menor: Aranzadi.

Cachón Cadenas, M. y Reynal Quirol, N. (2015). Concurrencia de acciones colectivas y acciones individuales para la protección de derechos e intereses de consumidores y usuarios. Revista Jurídica de Catalunya, 2, 144-150.

Carrasco Perera, A. (2017). El conundrum de la legitimación individual autónoma frente a las acciones restitutorias colectivas (en materia de cláusula suelo). SSTC 3 y 4/2017, Revista CESCO de Derecho de Consumo, 22, 175-177.

Planchadell Gargallo, A. (2014). Las «acciones colectivas» en el ordenamiento jurídico español. Valencia: Tirant lo Blanch.

Tapia Fernández, I. (2000). El objeto del proceso. Alegaciones. Sentencia. Cosa juzgada. Madrid: La Ley. 